\title{
General process, dynamics and modelling of radiocaesium cycling in contaminated forest: A whole-ecosystem approach
}

\author{
F. Goor and Y. Thiry \\ CEN-SCK, Radiation Protection Research Department, Boeretang 200, 2400 Mol, Belgium
}

\begin{abstract}
We used a chronosequence approach to compare the distribution of ${ }^{137} \mathrm{Cs}$ and potassium (K) in the different compartments of three Scots pine stands. The cycling dynamic of both element was assessed as a function of stand development with emphasis on ${ }^{137} \mathrm{Cs}$ immobilisation in wood. ${ }^{137} \mathrm{Cs}$ and $\mathrm{K}$ redistribute rather similarly between tree components, by circulating through the same pathways. ${ }^{137} \mathrm{Cs}$ immobilization in wood is, however, more important than for $\mathrm{K}$, especially in old stands. Although the old stand accumulated more ${ }^{137} \mathrm{Cs}$ from the Chernobyl event than the young stand, a much less limited pool of ${ }^{137} \mathrm{Cs}$ characterises its current annual cycling when compared to $\mathrm{K}$. Differences in the current ${ }^{137} \mathrm{Cs}$ content between young and old stands most likely reflect divergences occurred during the early redistribution rates after the fallout connected with differences in ${ }^{137} \mathrm{Cs}$ interception rate. The WIP approach (combining ${ }^{117} \mathrm{Cs}$ radial partern and biomass increment) was then preferred to the TF coefficient concept to quantify the actual ${ }^{137} \mathrm{Cs}$ immobilization in wood of each stand due to root uptake. Independently of the stand age, higher WIP values were related with the higher bio-availability of the ${ }^{137} \mathrm{Cs}$ located in organic layers.
\end{abstract}

\section{INTRODUCTION}

In comparison with agricultural cropping systems, forest ecosystem can produce and accumulate a considerable amount of biomass. Because of its important interception capacity and biomass recycling rate, the forest area act as an efficient long term storage of various atmospheric contaminants. This feature was well illustrated by the post-Chernobyl radioactive fallout which affected large forested area with long-lived radionuclides such as ${ }^{137} \mathrm{Cs}$ and ${ }^{90} \mathrm{Sr}$, especially in $\mathrm{CIS}$ and to a lesser extent in Western Europe. Several in situ studies made after the Chernobyl accident revealed a much higher recycling of radiocaesium in contaminated forest compared with agricultural area [1]. The persistence of an important bio-available pool of radioceasium in humus layers is mostly responsible of its long-lasting transfer to forest vegetation [2]. Among tree components, stemwood which strictly accumulates with time, represents the most important biomass compartment and was identified in many situations as the main reservoir for radiocaesium in forest trees, with great concern for local forest management and wood industry [3].

In fact, the process of trace contaminant (like radiocaesium) immobilization in wood is only a part of the conceptual biological cycling ensuring a permanent circulation of the nutrient between the soil and the tree. The recycling efficiency and then the immobilisation vary in function of the element considered as well as of the tree species and of the development stage of the stand [4]. Depending on the forest ecological conditions, the evolution of ${ }^{137} \mathrm{Cs}$-contaminated wood stock is thus expected to considerably diverge in space and time. The variability in cycling dynamic between forest types makes difficult the parameterisation of the relation between ${ }^{137} \mathrm{Cs}$ uptake/immobilisation by trees and its availability in forest soil. Its study thus involves the soil-plant system as a whole in a time scale well-suited with the longevity of the soil-plant system i.e. taking into account each stage of the ecosystem development [5].

In this study, the distribution of ${ }^{137} \mathrm{Cs}$ and potassium $(\mathrm{K})$ in the different compartments of three Scots pine stands (17,37 and 57 years old) was measured and their cycling dynamic assessed. The particular features of ${ }^{137} \mathrm{Cs}$ are identified and compared to $\mathrm{K}$. Special attention is paid to the trunk wood for which a best estimate of ${ }^{137} \mathrm{Cs}$ accumulation rate is deduced and compared to the pool of ${ }^{137} \mathrm{Cs}$ available in soil for 
root uptake. Finally, some perspectives for new developments in modelling of ${ }^{137} \mathrm{Cs}$ cycling in combination with GIS tools are discussed.

\section{RESULTS AND DISCUSSION}

\subsection{Element distribution in tree components}

In order to assess the distribution of ${ }^{137} \mathrm{Cs}$ and $\mathrm{K}$ in the different forest parts, the total biomass of each tree component was computed on the basis of biomass production tables. The measured concentrations of tree component samples weighted by their biomass were then used to calculate the total element content per component and per stand (Fig. 1).

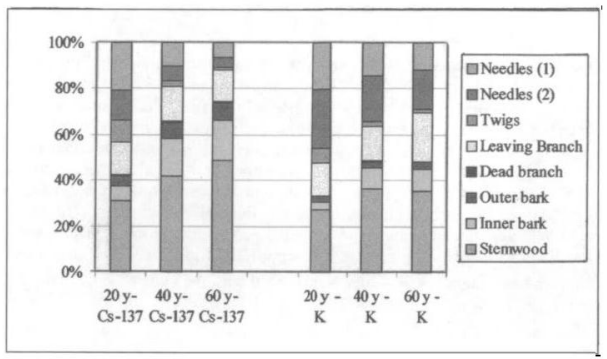

Figure 1: Relative ${ }^{137} \mathrm{Cs}$ and $\mathrm{K}$ distribution between pine tree compartments as a function of the age

In comparison to other major nutrients, potassium is characterized by a high mobility in tree [6]. Hence, the similarity between ${ }^{137} \mathrm{Cs}$ and $\mathbf{K}$ distributions as observed fifteen years after the Chemobyl deposits suggests a rapid assimilation of radiocaesium into the biological cycling. At the stand level, the foliage compartment dominated for $\mathrm{K}$ in the young plantation while stemwood becomes more important in the older stands, especially due to biomass increase. In each stand, the contribution of ligneous organs (stemwood and branches) to the total element content in tree is, however, higher for ${ }^{137} \mathrm{Cs}$ compared to $\mathrm{K}$ and this contribution increases with tree age. This picture provides indications that stemwood acts as a main sink for radiocaesium. Stemwood behaves in fact as a chromatographic column for xylem sap containing elements which originate without distinction from root uptake or from retranslocation. The higher relative accumulation of ${ }^{137} \mathrm{Cs}$ in woody components lets suppose that, in addition to root uptake, the ${ }^{137} \mathrm{Cs}$ initial interception and its subsequent foliar absorption and translocation in mature trees were influential. The assessment of the biological cycling in stands with different ages allows to distinguish the main processes controlling the element dynamics [5] [7] and is therefore a prerequisite to predictive modelling of the ${ }^{137} \mathrm{Cs}$ accumulation in tree.

\subsection{Assessment of the element cycling}

A well-documented calculation methodology [4] [5] [7] was adapted to quantify the annual nutrient fluxes, both into and out of the tree, from the elements and biomass content in the contaminated stands. Such estimation of the biological cycling allowed to compare the ${ }^{137} \mathrm{Cs}$ and $\mathrm{K}$ current mobilisation rates in the young and old stands (table 1 ).

The results shows that the $\mathrm{K}$ annually incorporated in new organs (requirement) as the $\mathrm{K}$ absorbed by roots from the soil available pool (uptake) decrease slightly with stand ageing. The inverse trend is observed for $\mathrm{K}$ internal transfer. The contribution of recycled $\mathrm{K}$ to tree nutrition functioning is very important and increases with time when compared to uptake, demonstrating the capacity of forest trees to 
optimise the nutrient use by mobilising K "reserve" of the tree. Litterfall and leaching return to the soil a major and increasing part of the $\mathrm{K}$ uptake with time. This lead to a limited $\mathrm{K}$ annual immobilisation which decreases significantly in the older stand. These results are in good agreement with those of other authors for $\mathrm{K}$ cycling in pine trees [8] and other coniferous [5]. They give an opportune basis for assessment of the ${ }^{137} \mathrm{Cs}$ cycling in trees which is usually characterised by transport pathways similar to those of $\mathrm{K}$.

Table 1: Annual fluxes of the biological cycling in the young and the old pine stands

\begin{tabular}{|c|c|c|c|c|c|c|c|c|}
\hline \multirow{3}{*}{ Fluxes } & \multicolumn{4}{|c|}{17 years } & \multicolumn{4}{|c|}{57 years } \\
\hline & \multicolumn{2}{|r|}{$K$} & \multicolumn{2}{|r|}{${ }^{137} \mathrm{Cs}$} & \multicolumn{2}{|r|}{$\mathbf{K}$} & \multicolumn{2}{|r|}{${ }^{137} \mathrm{Cs}$} \\
\hline & $\mathrm{kg} \cdot \mathrm{ha}^{\prime}$ & $\%$ of uptake & MBq.ha ${ }^{-1}$ & $\%$ of uptake & $\mathrm{kg} \cdot \mathrm{ha}^{-1}$ & $\%$ of uptake & $\mathbf{M B q} \cdot \mathrm{h}^{-1}$ & $\%$ of uptake \\
\hline (1) "Requirement" & 21.5 & & 293,0 & & 18.5 & & 122,1 & \\
\hline (2) Return & 3,4 & 49 & 33,2 & 42 & 3,9 & 63 & 24,5 & 52 \\
\hline (3) Immobilisation & 3,6 & 51 & 45,0 & 58 & 2,4 & 37 & 22,3 & 48 \\
\hline$(2)+(3)$ Uptake & 6,9 & & 78,2 & & 6,3 & & 46,8 & \\
\hline (4) Internal transfer & 14,1 & 203 & 188,5 & 241 & 14.4 & 228 & 94,1 & 201 \\
\hline
\end{tabular}

In these conditions, a tentative comparison can be made between ${ }^{137} \mathrm{Cs}$ and $\mathrm{K}$ annual fluxes assuming that a certain stabilisation of the ${ }^{137} \mathrm{Cs}$ redistribution in contaminated forest is achieved 15 years after the radioactive atmospheric fallout. Compared to $\mathrm{K}$, we observed that annual ${ }^{137} \mathrm{Cs}$ requirement is more importantly reduced in the old stand. Changes in ${ }^{137} \mathrm{Cs}$ uptake with age show the same trend but to a lesser extent. While the absolute amounts of $\mathrm{K}$ which return to the soil increase with age, those of ${ }^{137} \mathrm{Cs}$ are lowered but still represent an increasing part of the uptake similarly to that of $\mathrm{K}$. The ${ }^{137} \mathrm{Cs}$ immobilisation presents a similar pattern to that of $\mathrm{K}$ with two times less ${ }^{137} \mathrm{Cs}$ incorporated in ligneous organs of the old stand in comparison to the young stand. However, the part of the ${ }^{137} \mathrm{Cs}$ uptake used for building up woody biomass increment remains higher than that of $\mathrm{K}$, especially in the old stand, confirming a key-role of woody biomass as a long term sink for ${ }^{137} \mathrm{Cs}$. The internal transfer of $\mathrm{K}$ was shown to play a growing role in the oldest tree nutrition. Although the ${ }^{137} \mathrm{Cs}$ is shown to be less recycled in the old stand than in the young stand, it still contributes to the mobilisation of a major amount of ${ }^{137} \mathrm{Cs}$, corresponding to two times the amount of ${ }^{137} \mathrm{Cs}$ absorbed by roots.

These results confirm that both ${ }^{137} \mathrm{Cs}$ and $\mathrm{K}$ redistribute rather similarly between tree components, by circulating through the same pathways. A very high rate of intemal transfer is, in particular, a common feature of ${ }^{137} \mathrm{Cs}$ and $\mathrm{K}$ cycling dynamic in pine. However, we observed greater differences in the real amounts of ${ }^{137} \mathrm{Cs}$ involved in elemental cycling of each stand than for $\mathrm{K}$, and which can be the result of (1) the lasting effect of the early redistribution of ${ }^{137} \mathrm{Cs}$ after the fallout on the current cycling dynamic, (2) important differences in the ${ }^{137} \mathrm{Cs}$ availability in soil compared to $\mathrm{K}$.

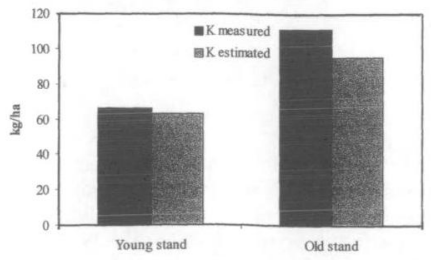

A.

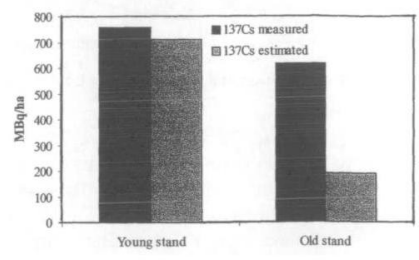

B.

Figure 2: Comparison between measured inventory of $\mathrm{K}$ (A) and of ${ }^{137} \mathrm{Cs}(\mathrm{B})$ in trees and the amount estimated from fluxes data 
With time, a much less limited pool of ${ }^{137} \mathrm{Cs}$ characterises the annual cycling functioning of the old stand. The ${ }^{137} \mathrm{Cs}$ root uptake in particular is reduced, proportionally to other fluxes, thus suggesting a prevailing role of soil available ${ }^{137} \mathrm{Cs}$ to explain changes in ${ }^{137} \mathrm{Cs}$ accumulation rates between stands. To deal with this assumption, we used the present fluxes data to reconstruct a balance for total $\mathrm{K}$ and ${ }^{137} \mathrm{Cs}$ in tree and to assess the element amount of the soil reserve respectively involved in each stand growth during the entire rotation for $\mathrm{K}$ and from the Chemobyl contamination event for ${ }^{137} \mathrm{Cs}$ (see Fig. 2). The estimated amount of the element incorporated in tree biomass f.e. taken up from the soil to sustain the stand development are in good agreement with the measured values for $\mathrm{K}$ in both the young and the old stand. The same is true for ${ }^{137} \mathrm{Cs}$ in the young stand but not in the old stand for which the estimated ${ }^{137} \mathrm{Cs}$ content in tree represents only $35 \%$ of the measured value. That means that differences in the current ${ }^{137} \mathrm{Cs}$ content between young and old stands reflect probably also divergences occurred in the early redistribution rates after the fallout connected with differences in canopy development and ${ }^{137} \mathrm{Cs}$ interception. In other terms, the initial ${ }^{137} \mathrm{Cs}$ interception and subsequent translocation to structural components still affect, in addition to root uptake, the total ${ }^{137} \mathrm{Cs}$ content in standing biomass of the old stand. This feature can obscure the parametrization of the relationship between ${ }^{13 ?} \mathrm{Cs}$ availability in soil and its cycling rates or, more particularly, its trends of accumulation in wood with time. Nowadays, the soil is the predominant source of available ${ }^{137} \mathrm{Cs}$ and will affect primarily the future contamination of young stands. Hence, the role of root uptake in ${ }^{137} \mathrm{Cs}$ accumulation in wood of old stands needs to be verified with accurate assessment.

\subsection{Radiocaesium accumulation in trunk wood}

Radiocaesium is mobile in stemwood of pine but accumulates differently on the radial transect as a function of tree age, leading accordingly to varying radial gradient [9]. This radial mobility of ${ }^{137} \mathrm{Cs}$ in trunk complicates the estimation a priori of the ${ }^{137} \mathrm{Cs}$ levels associated with the production of new annual wood rings. With some hypotheses (quasi-equilibrium of ${ }^{137} \mathrm{Cs}$ radial redistribution, no important change of ${ }^{137} \mathrm{Cs}$ bio-availability from the soil in the near future), the variation of ${ }^{137} \mathrm{Cs}$ content (or ${ }^{137} \mathrm{Cs}$ accumulation rate) in trunk can nevertheless be deduced from the volume and the present ${ }^{137} \mathrm{Cs}$ level in wood rings, as schematised in Fig. 3.

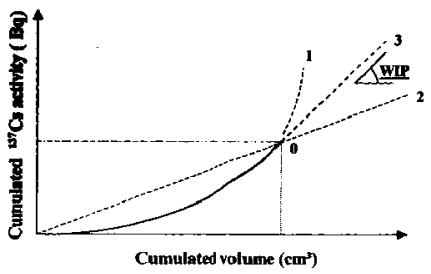

Figure 3: Conceptual definition of the ${ }^{137} \mathrm{Cs}$ immobilisation potential in wood (WIP)

In this figure, the plain curve is plotted by summing as $x$ - and $y$-axes, for each annual increment from the pith to the outermost ring, respectively the volume of stemwood $\left(\mathrm{cm}^{3}\right)$ and its ${ }^{137} \mathrm{Cs}$ content (Bq). In other words, this curve represents the present pattern of the accumulation of ${ }^{137} \mathrm{Cs}$ in trunk in function of the production of stemwood volume. The point 0 referring to the present situation, the WIP $\left({ }^{137} \mathrm{Cs}\right.$ immobilisation potential in wood), defined as the first derivative of the curve at this point, is a best estimate of the present rate of ${ }^{137} \mathrm{Cs}$ accumulation in stemwood $\left(\mathrm{Bq} / \mathrm{cm}^{3}\right)$ [9]. In practice, the WIP is approximated by the mathematical slope of the straight line fitted on the 5-10 last points of the curve (i.e., the 5-10 outermost wood rings of the trunk). For the whole trunk, the WIP's calculated at different heights are weighted by the volume of the corresponding trunk part. 
The WIP approach (Fig. 3, curve 3) is a compromise between two extremes: a conservative approach (each ring has the memory of the annual uptake episode, no ${ }^{137} \mathrm{Cs}$ redistribution in the trunk ; Fig. 3, curve 1) and the Transfer Factor (TF) approach (no radial gradient of ${ }^{137} \mathrm{Cs}$, homogeneous redistribution of ${ }^{137} \mathrm{Cs}$ in stemwood ; Fig. 3, curve 2). Widely used, the latter expresses the ratio of the average radionuclide concentration in a given plant compartment $\left(\mathrm{Bq} \mathrm{kg}^{-1}\right)$ to that in the soil $\left.\left(\mathrm{Bq} \mathrm{kg}^{-1} \text { or } \mathrm{Bq} \mathrm{m}\right)^{-2}\right)$. In Table 2, the WIP values are compared with the conventional TF values and interpreted in terms of net soil-to-wood fluxes for the three stands studied.

Table 2: Quantification of the ${ }^{193} \mathrm{Cs}$ immobilisation rate in the three pine stands

\begin{tabular}{|c|c|c|c|}
\hline Immobilisation in perennial biomass (trunk wood) & 17 years & 37 years & 57 years \\
\hline \multicolumn{4}{|l|}{ Measured } \\
\hline Transfer Factor $\left(m^{2} / \mathrm{kg}\right)$ & $0,00288 \pm 0,00063$ & $0,00139 \pm 0,00042$ & $0,00197 \pm 0,00108$ \\
\hline Total Cs-137 content in wood ( $\%$ Cs-137 in soil) & $0,99 \pm 0,26$ & $2,42 \pm 0,53$ & $2,96 \pm 1,91$ \\
\hline \multicolumn{4}{|l|}{ Colculated } \\
\hline WIP Cs-137 (B $\left./ / \mathrm{cm}^{3}-\mathrm{y}\right)$ & $2,49 \neq 0,13$ & $1,21 \pm 0,21$ & $1,76 \pm 0,97$ \\
\hline Annual Cs-137 flux to wood ( $\% \mathrm{Cs}-[37$ in soil) & $0,090 \pm 0,003$ & $0,112 \pm 0,017$ & $0,077 \pm 0,048$ \\
\hline Cs- 137 content in wood due to root uptake ( $\% \mathrm{Cs}-137$ in soil) & $1,07 \pm 0,03$ & $1,67 \pm 0,25$ & $1,16 \pm 0,71$ \\
\hline
\end{tabular}

The TF and WIP values evolve similarly between the three stand ages (the ratio TF/WIP is constant). Nevertheless, the ${ }^{137} \mathrm{Cs}$ measured in tree compartments originates most likely from both the interception by the canopy of initial atmospheric deposits and root uptake. Based on average ${ }^{137} \mathrm{Cs}$ levels in soil and tree, the TF's, contrary to the WIP's, are not efficient to predict the distinctive contribution of the root uptake process which rules the long term ${ }^{137} \mathrm{Cs}$ accumulation in wood. According to Fig. 3, the TF's underestimate the ${ }^{137} \mathrm{Cs}$ accumulation rate by a factor of 32 to $41 \%$ when compared to WIP values. In the young stand, the WIP multiplied by the time spent from the Chemobyl accident (12 years) is in good agreement with the measured total ${ }^{137} \mathrm{Cs}$ content in stemwood (Table 2). At the time of contamination, the canopy of such young trees was not very developed and the most part of the present ${ }^{137} \mathrm{Cs}$ content in stemwood is attributable to root uptake. The same calculation points out that soil-to-wood transfer explains respectively 55 and $31 \%$ of the measured total ${ }^{137} \mathrm{Cs}$ content in wood of the 37 - and 57 -years old stands, highlighting the lasting influence of the initial fallout interception by well-developed canopies on the wood contamination.

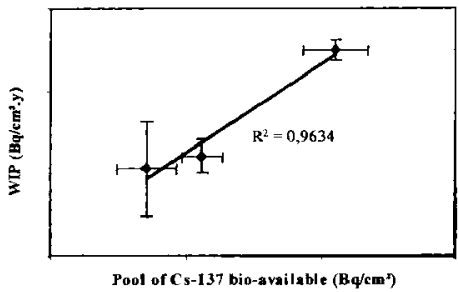

Figure 4: Relation between the ${ }^{137} \mathrm{Cs}$ availability in soil and its immobilisation in wood connected with volume increment

Conversely, the WIP seems more adequate to make the link with the pool of ${ }^{137} \mathrm{Cs}$ bio-available in the soil. The root uptake contribution is expected to largely vary depending on the age of the stands because of changes in humus thickness and in the vertical profile of ${ }^{137} \mathrm{Cs}$ content. The ${ }^{137} \mathrm{Cs}$ bio-availability was determined in the three forest stands using a standardised biological extraction test [10]. In the three forest stands, the pools of ${ }^{137} \mathrm{Cs}$ available for root uptake, calculated as a function of the depth, of the ${ }^{137} \mathrm{Cs}$ content and of the ${ }^{137} \mathrm{Cs}$ bio-availability in the organic surface layers, are proportional to the WIP values 
(Fig. 4). Such relation between the main source (soil) and sink (stemwood) of ${ }^{137} \mathrm{Cs}$ proves the ability of the WIP to isolate the distinctive contribution of the root uptake process.

\subsection{Perspeetives in modelling and GIS development}

The identification and dynamical description of the key-processes of ${ }^{137} \mathrm{Cs}$ cycling in forest ecosystems developed above opens new perspectives in the frame of modelling and provides opportunities for verifications. Indeed, the existing radioecological models simulate the ${ }^{137} \mathrm{Cs}$ cycling within forest stands using fixed TF's or first order transfer equations between soil and tree compartments (IAEA, 2000). Stemwood is most often considered as an homogeneous pool with an average ${ }^{137} \mathrm{Cs}$ concentration. In these conditions, it is not possible to make the link between root uptake and accumulation in stemwood nor to consider its relationship with essential biological processes like the internal retranslocation of ${ }^{137} \mathrm{Cs}$ within the tree. This has important consequences in terms of accuracy of long term simulations. For example, the agreement between the predictions of several models of ${ }^{137} \mathrm{Cs}$ transfer in forest ecosystems for a same contamination scenario was shown to decrease with time for the stemwood compartment in particular [11]. In this respect, dynamic parameters like the WIP can improve the understanding and the description of ${ }^{137} \mathrm{Cs}$ fluxes and form the basis of a common approach for the ${ }^{137} \mathrm{Cs}$ cycling modelling in forest ecosystems of various ages and ecological conditions.

Such a common approach is also useful for improving forest categorisation in terms of vulnerability or

${ }^{137} \mathrm{Cs}$ critical loads as well as to perform GIS developments, as conducted for a preliminary study of establishment of willow short rotation coppices on contaminated farmlands in a district of Ukraine [12]. The spatial issue was to evaluate and localise ${ }^{139} \mathrm{Cs}$ inventory possibly related with wood resources available for conversion into energy for different time steps. A complementary approach would imply to consider as well the forest resources.

\section{Acknowledgments}

This research was partially supported by PSI (Paul Scherrer Institute, Switzerland) in the frame of a bilateral convention between CEN•SCK and PSI (CEN-SCK co-operation agreement: KNT 9097 1004).

\section{References}

[1] Myttenaere C., Schell W.R., Thiry Y., Sombre L., Ronneau C. and Van der Stegen, J., Science of the Total Environment 136 (1993) 77-91.

[2] Thiry Y., Kruyts N. and Delvaux, B., J. Environ. Qual. 29 (2000) 1194-1199.

[3] Ipatyev V., Bulavik V., Baginsky G., Goncharenko G. and Dvornik A., J. Environ. Radioactivity 42 (1999) 9-38.

[4] Ranger J. \& Bonneau M., R.F.F. 36-2 (1984) 93-111.

[5] Ranger J., Marques R., Colin-Belgrand M., Flammang N. and Gelhaye, D., Forest Ecology and Management 72 (1995) 167-183.

[6] Van der Stegen J. and Myttenaere C., Trends in Soil Sciences 1 (1991) 271-276.

[7] Ulrich B., Influence de la fertilisation sur le cycle des éléments nutritifs dans les écosystèmes

forestiers. C.R. Congrès Paris 1973, IUFRO/FAO, pp. 23-34.

[8] Helmisaari H.S., Forest Ecology and Management 51 (1992) 347-367.

[9] Thiry Y., Goor F, and Riesen Th., $J$. Environ. Radioactivity (2001) 1-17, in press.

[10] Kruyts N., Thiry Y. and Delvaux, B., J. Environ. Qual. 29 (2000) 1180-1185.

[11] Avila R., Bergman R., Scimone M., Fesenko S., Sancharova N. and Moberg, L., J. Environ.

Radioactivity 55 (2001) 315-327.

[12] Goor F., Davydchuk V. and Ledent J.-F., Biomass and Bioenergy (2001) in press. 